\title{
The Effect of ZnO Thin Film and Its Structural and Optical Properties Prepared by Sol-Gel Spin Coating Method
}

\author{
Nagarani Nagayasamy, Saroja Gandhimathination, Vasu Veerasamy \\ School of Physics, Madurai Kamaraj University, Madurai, India \\ Email: nagarani1966@gmail.com
}

Received March 28, 2013; revised April 28, 2013; accepted May 5, 2013

Copyright (C) 2013 Nagarani Nagayasamy et al. This is an open access article distributed under the Creative Commons Attribution License, which permits unrestricted use, distribution, and reproduction in any medium, provided the original work is properly cited.

\begin{abstract}
$\mathrm{ZnO}$ thin films were deposited on glass substrates at different Zinc concentration and their effects on structural, morphology and optical properties were investigated. Zinc acetate dehydrate, 2 Methoxy ethanol and Monoethanolamine were used as the precursor, solvent and stabilizer respectively. The molar ratio of Monoethanolamine to Zinc acetate was maintained as 1 . The crystal structure and orientation of the films were analyzed by XRD. The XRD patterns show that the $\mathrm{ZnO}$ films are polycrystalline with wurtzite hexagonal structure. The film with $0.5 \mathrm{~m} / 1$ concentration has the better crystallinity. The thickness of the films was determined by thickness Profilometer. The surface morphology of the films was observed by Scanning electron microscope. The SEM images show that they are homogeneous, continuous and spindle like shape. The optical properties of the films were studied by UV-Vis-Spectrophotometer. The transmittance of the films decreases with increase of Zinc concentration. The energy band gap of the films decreases slightly, when the Zinc concentration increases from $0.25 \mathrm{~m} / 1$ to $0.75 \mathrm{~m} / 1$ and then increases when the concentration further increases from $0.75 \mathrm{~m} / 1$ to $1.0 \mathrm{~m} / \mathrm{l}$.
\end{abstract}

Keywords: ZnO Thin Films; Sol-Gel; XRD; SEM; Optical Properties

\section{Introduction}

Zinc Oxide is an important, inexpensive, versatile n-type semiconducting material with wide direct energy band gap of $3.37 \mathrm{eV}$ and large exciton binding energy of about $60 \mathrm{meV}$ at room temperature. $\mathrm{ZnO}$ has unique structural, optical and electrical properties. Due to its high transparent conducting properties, it has many potential applications like light emission display devices, piezoelectric transducers, surface acoustic devices, optoelectronic devices etc., Various deposition techniques were employed for the preparation of $\mathrm{ZnO}$ thin films such as magnetron sputtering [1], spray pyrolysis [2], pulsed laser deposition [3], electron beam evaporation [4] and sol-gel method [5-9]. In this work the $\mathrm{ZnO}$ films were prepared by an inexpensive sol-gel spin coating technique and studied the effect of concentration of the precursor on structural, morphological and optical properties.

\section{Experimental Details}

$\mathrm{ZnO}$ thin films were coated on glass substrates by sol-gel method. Zinc acetate dehydrate, 2 Methoxy ethanol and Monoethanolamine were used as the precursor, solvent and stabilizer respectively. Zinc acetate dehydrate was dissolved in a mixture of 2 Methoxy ethanol and Monoethanolamine at room temperature. The molar ratio of MEA to Zinc acetate was maintained as 1 and the concentration of Zinc acetate were $0.25 \mathrm{~m} / 1,0.5 \mathrm{~m} / 1,0.75$ $\mathrm{m} / 1$ and $1.0 \mathrm{~m} / 1$ respectively. The solutions were stirred at $60^{\circ} \mathrm{C}$ for $2 \mathrm{hrs}$ to yield a clear and homogeneous solution. All of the solutions were then aged at room temperature for 1 day before spin coating.

The substrates were cleaned by soap solution, chromic acid, distilled water, acetone and finally with deionized water. Then the films were deposited on the glass substrates using spin coater. The substrates were spin at $3000 \mathrm{rpm}$ for $30 \mathrm{sec}$. while the solution was dropped on to a glass substrate. In order to evaporate the solvent and remove the organic residuals the films were preheated at $300^{\circ} \mathrm{C}$ for 10 minutes after each Coating. This process was repeated several times. Then the films were annealed at $500^{\circ} \mathrm{C}$ for 1 hour.

The structure and orientation of the $\mathrm{ZnO}$ thin films 
were analyzed by $\mathrm{X}$-ray diffractometer with $\mathrm{Cu}-\mathrm{K}_{\alpha}$ radiation. The thickness of the films was determined by thickness profile meter. The surface morphology of the films was observed by Scanning electron microscope. The optical properties of the films were carried out by UV-Vis spectrophotometer.

\section{Results and Discussions}

\subsection{Structural Properties XRD}

Figure 1 shows the XRD pattern of $\mathrm{ZnO}$ thin films prepared at different Zinc concentrations and annealed at $500^{\circ} \mathrm{C}$ for 1 hour. From the figure it may be observed that there are only three peaks with the (100) (002) (101) orientation for the sample of $0.25 \mathrm{~m} / 1$ and $0.5 \mathrm{~m} / 1$ concentrations. The number of orientation increases to six for the sample $0.75 \mathrm{~m} / 1$ and seven for the sample $1.0 \mathrm{~m} / 1$ concentration. Further it may be noted that the prepared orientation for $0.25 \mathrm{~m} / 1$ and $0.5 \mathrm{~m} / 1$ samples was (002) and for higher concentration (that is above $0.5 \mathrm{~m} / \mathrm{l}$ ) sample the preferred orientation was (101). The XRD results show that all the films were polycrystalline wurtzite hexagonal structure and have no preferred orientation. This may be due to the preferred orientation is weakened when the $\mathrm{Zn}$ concentration increases. The grain size of the film was calculated for different Zinc concentration by using Scherrer's formula [10]

$$
D=\frac{0.9 \lambda}{\beta \cos \theta}
$$

where $\lambda$ is the wavelength of the $\mathrm{X}$-ray radiation used. $\beta$ is the Full width Half Maximum and $2 \theta$ is the highest diffraction angle. The strain in the films were calculated using the formula

$$
\varepsilon=\frac{\beta \cos \theta}{4}
$$

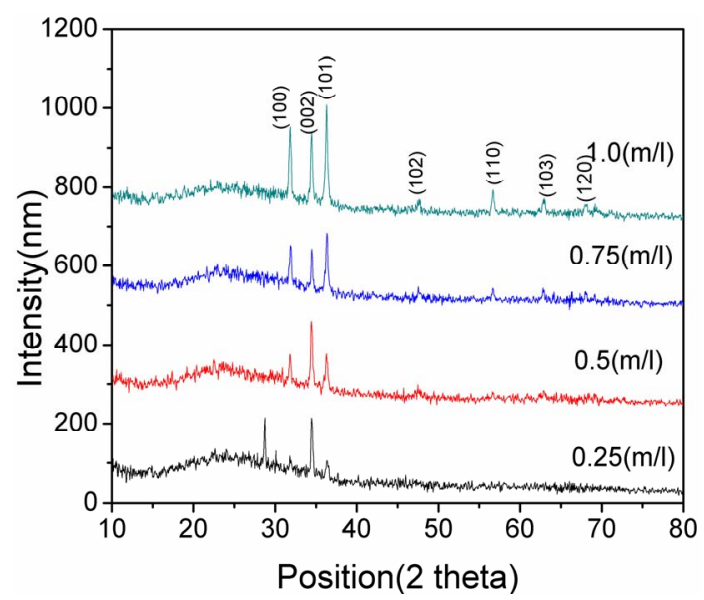

Figure 1. XRD spectra of $\mathrm{ZnO}$ thin films at different Zinc concentration (a) $0.25 \mathrm{~m} / \mathrm{l}$; (b) $0.5 \mathrm{~m} / \mathrm{l}$; (c) $0.75 \mathrm{~m} / 1$ (d) 1.0 $\mathbf{m} / \mathbf{l}$.
The value of particle size, strain and FWHM values are tabulated in Table 1. From the table it may be observed that the strain value of the film decreases with increase in particle size. For the concentration of $0.5 \mathrm{~m} / 1$, FWHM value is very small indicating larger particle size compared to other concentrations.

Figures 2 (a) and (b) show the relation between strain and particle size of the films as a function of Zinc acetate concentration. The thickness of the film was tabulated in Table 1. It may be observed that the thickness of the film increases with increase of Zinc Concentration. This is because of the increased fluid Viscosity.

\subsection{Surface Morphology}

Figures 3 (a)-(d) show the SEM images of $\mathrm{ZnO}$ thin films for different concentration of $\mathrm{ZnO} 0.25 \mathrm{~m} / 1,0.5 \mathrm{~m} / 1$, $0.75 \mathrm{~m} / 1$ and $1.0 \mathrm{~m} / 1$ deposited on glass substrates. The films deposited at different concentration have smooth and spindle like structure and uniformly covering the overall surfaces with good adherence. The SEM images show the grains of spindle like shape without any cracks and pores.

\subsection{Optical Properties}

Figure 4 shows the optical transmittance spectra of $\mathrm{ZnO}$

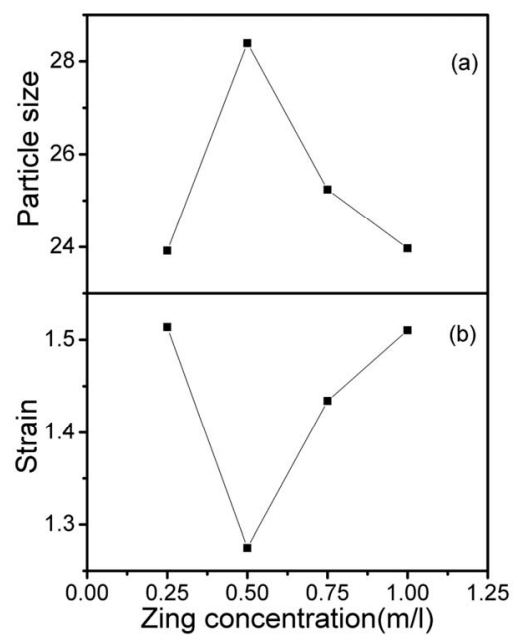

Figure 2. (a), (b) the relation between strains, particle size with respect to Zinc concentration.

Table 1. The structural parameters of the $\mathrm{ZnO}$ thin films.

\begin{tabular}{cccccccc}
\hline $\begin{array}{c}\text { Zinc } \\
\text { concentration }\end{array}$ & $\begin{array}{c}\text { Position } \\
(2 \theta)\end{array}$ & $(\mathrm{hkl})$ & FWHM & $\begin{array}{c}\text { Strain } \\
(\beta \cos \theta / 4)\end{array}$ & $\begin{array}{c}\text { Particle } \\
\text { size }(\mathrm{nm})\end{array}$ & $\begin{array}{c}\text { Thickness } \\
(\mu \mathrm{m})\end{array}$ \\
\hline $0.25 \mathrm{~m} / 1$ & 34.4672 & $(002)$ & 0.3634 & 1.5137 & 23.92 & 0.26 \\
$0.50 \mathrm{~m} / 1$ & 34.4367 & $(002)$ & 0.3061 & 1.2751 & 28.39 & 0.40 \\
$0.75 \mathrm{~m} / 1$ & 36.3110 & $(101)$ & 0.3461 & 1.4342 & 25.24 & 0.44 \\
$1.00 \mathrm{~m} / 1$ & 36.2727 & $(101)$ & 0.3644 & 1.5102 & 23.97 & 0.49 \\
\hline
\end{tabular}




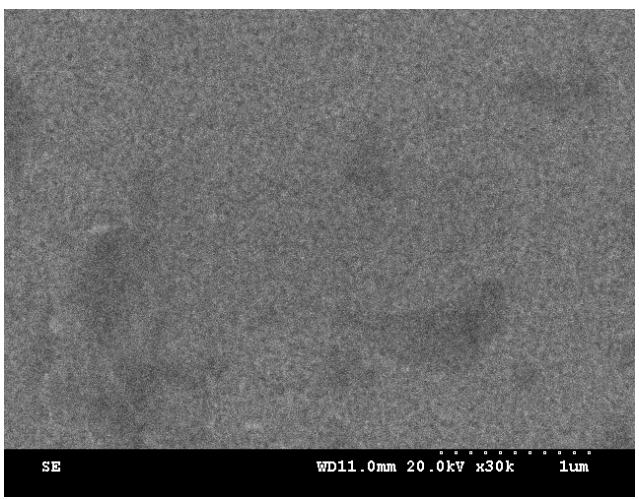

(a)

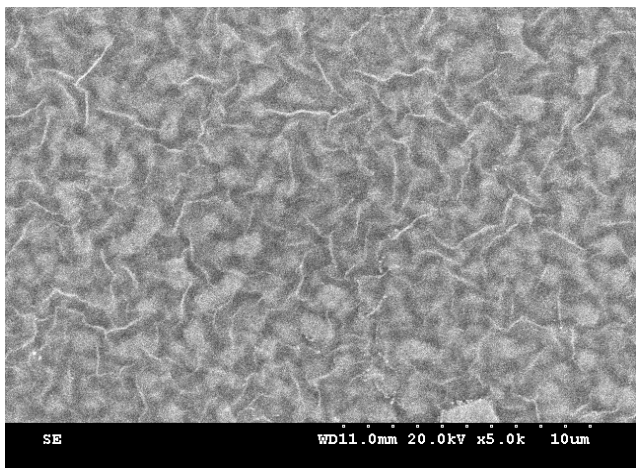

(b)

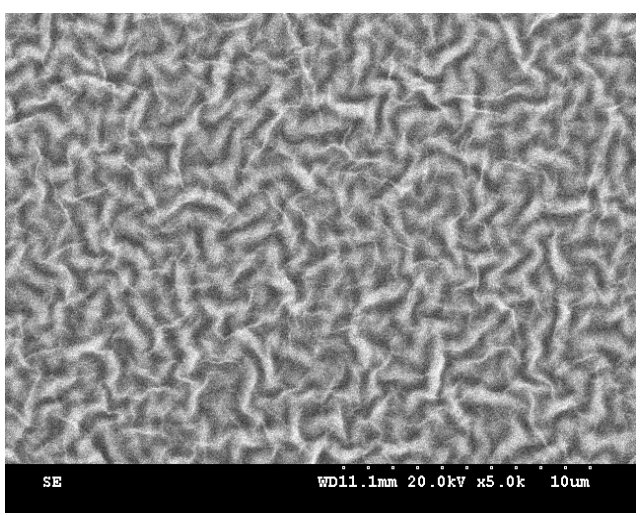

(c)

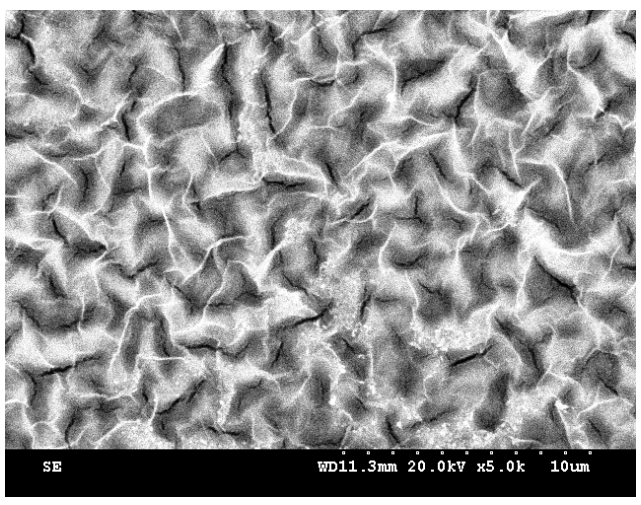

(d)

Figures 3. (a)-(c) show the surface morphology of the films at different Zinc concentration.

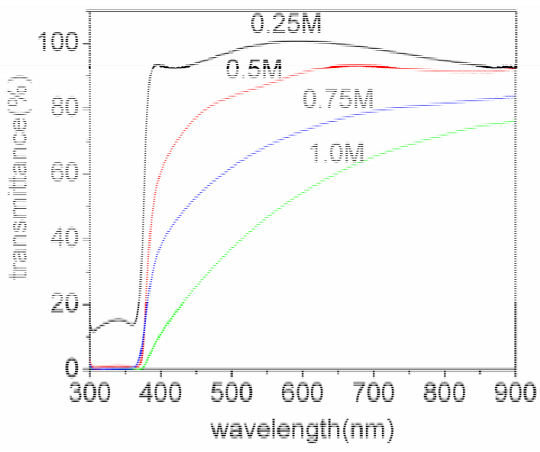

Figure 4. Transmittance spectra of $\mathrm{ZnO}$ films with different Zn concentration.

films with different Zinc concentration. The transmittance decreases with increase of Zinc concentration. All the samples present a sharp absorption edge in the UV region nearly $370 \mathrm{~nm}$ due to the onset fundamental absorption. The decrease in transmittance may be due to increase of the optical scattering caused by the grain boundaries and the increase in film thickness. The grain boundary density increases with increasing Zinc concentration. This may reduce the optical transmittance. The absorption co-efficient $(\alpha)$ was determined from the transmittance measurements using the relation

$$
\alpha=\frac{\ln (1 / T)}{t}
$$

where $T$ is the transmittance and $t$ is the thickness of the film. The calculated absorption co-efficient values are used to determine the optical energy gap of the films. Figure 5 shows the plot of $(\alpha h \gamma)^{2}$ versus $h \gamma$.

Assuming a direct transition between valance and conduction bands, the energy band gap was determined by the expression [11]

$$
\alpha h \gamma=k\left(h \gamma-E_{g}\right)^{1 / 2}
$$

where $k$ is the constant. $E_{g}$ is determined by extra ploting the straight line portion of the curve to $(\alpha h \gamma)^{2}=0$ and the values for different Zinc concentration are tabulated in Table 2. It may be observed that the energy band gap decreases slightly, when the concentration Increases from $0.25 \mathrm{~m} / 1$ to $0.75 \mathrm{~m} / 1$ and further increases when concentration Increases from $0.75 \mathrm{~m} / 1$ to $1.0 \mathrm{~m} / \mathrm{l}$.

\section{Conclusion}

$\mathrm{ZnO}$ thin films were prepared with different Zinc concentration and their effects on structural, morphology and optical properties were studied. The XRD results show that the films are polycrystalline wurtzite hexagonal structure and have no preferred orientation. The film with $0.5 \mathrm{~m} / 1$ concentration has minimum value of strain and has larger particle size compared to other concentrations. 


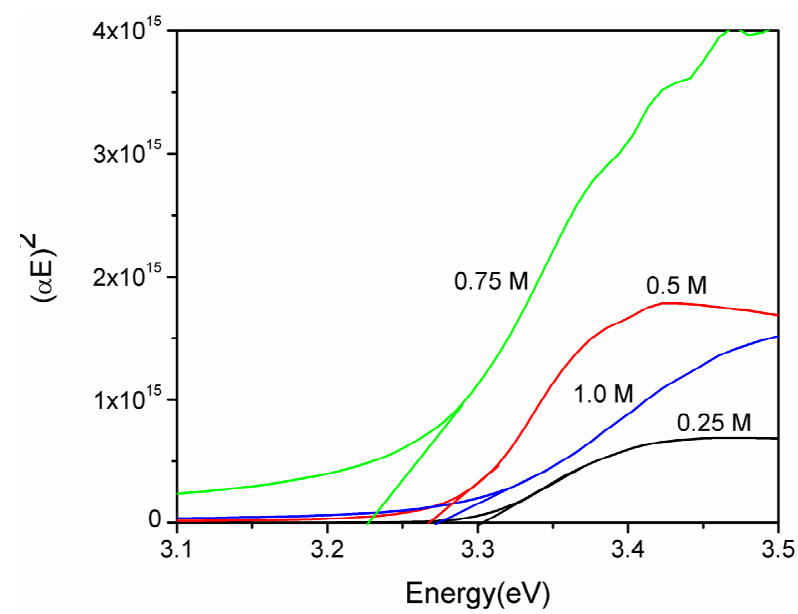

Figure 5. Band gap plot of $(\alpha h \gamma)^{2}$ versus $h \gamma$.

Table 2. Energy bandgap of ZnO films with different Zn concentration.

\begin{tabular}{cc}
\hline Zinc concentration $(\mathrm{m} / \mathrm{l})$ & Energy bandgap $(\mathrm{eV})$ \\
\hline 0.25 & 3.3054 \\
0.50 & 3.2695 \\
0.75 & 3.2295 \\
1.00 & 3.2757 \\
\hline
\end{tabular}

The thickness of the films increases with increase of Zinc concentration. SEM images show that they are homogeneous, continuous and spindle like shape. The transmittance decreases with increase of Zinc concentration. This may be due to increase of optical scattering caused by the grain boundary. The energy band gap of the films decreases slightly, when the Zinc concentration increases from $0.25 \mathrm{~m} / 1$ to $0.75 \mathrm{~m} / 1$ and then increases when the concentration further increases from $0.75 \mathrm{~m} / 1$ to $1.0 \mathrm{~m} / \mathrm{l}$.

\section{REFERENCES}

[1] H. Czternastek, "ZnO Thin Films Prepared by High Pressure Magnetron Sputtering," Optoelectronics Review, Vol. 12, No. 1, 2004, pp. 49-52.

[2] C. Gumu, O. M. Ozkendir, H. Kavak and Y. Ufuktepe, "Structural and Optical Properties of Zinc Oxide Thin
Films Prepared by Spray Pyrolysis Method," Journal of Optoelectronicics and Advanced Materials, Vol. 8, No. 1, 2006, pp. 299-303.

[3] A. Og. Dikovska, P. A. Atanasov, C. Vasileva, I. G. Dimitrov and T. R. Stovanchov, "Thin ZnO Films Produced by Pulsed Laser Deposition," Journal of Optoelectronics and Advanced Materials, Vol. 7, No. 30, 2005, pp. 1329-1334.

[4] D. C. Agarwal, R. S. Chanhan, Amit Kumar, D. Kabiraj, F. Singh, et al., "Synthesis and Charectarization of $\mathrm{ZnO}$ Thin Film Grown by Electron Beam Evoporation," Journal of Applied Physics, Vol. 99, No. 12, 2007, pp. 11-14.

[5] A. Singh, A. Kumar, N. Suri, S. Kumar, M. Kumar, P. K. Khanna and D. Kumar, "Structural and optical Charectarization of $\mathrm{ZnO}$ Thin Films Deposited by Sol-Gel Method," Journal of Optoelectronics and Advanced Materials, Vol. 11, No. 6, 2009, pp. 790-793.

[6] A. Y. Liu, J. Q. Zhang and Q. H. Wang, "Structural and Optical Properties of ZnO Thin Films Prepared by Different Sol-Gel Process," Chemical Engineering Communications, Vol. 198, No. 4, 2011, pp. 494-503.

[7] H. X. Li, J. Y. Wang, H. Liu, C. H. yang, H. Y. Xu, X. Li and H. M. Cui, "Sol-Gel Preparation of Transparent Zinc Oxide Films with Highly Preferential Crystal Orientation," Vaccum, Vol. 77, No. 1, 2004, pp. 57-62.

[8] S. Ilican, Y. Caglar and M. Cagler, "Preparation and Characterization of $\mathrm{ZnO}$ Thin Films Deposited by Sol-Gel Method," Journal of Optoelectronics and Advanced Materials, Vol. 10, No. 10, 2008, pp. 2578-2583.

[9] Z. R. Khan, M. Khan, M. Zulfquar and M. S. Khan, “Optical and Structural Properties of $\mathrm{ZnO}$ Thin Films Fabricated by Sol-Gel Method," Material Sciences and Applications, Vol. 2, 2011, pp. 340-345.

[10] Z. R. Khan, M. Zulfequar and M. S. Khan, "Optical and Structural Properties of Thermally Evaporated Cadmium Sulphide Thin Films on Silicon (1 00 ) Wafers," Materials Science and Engineering: B, Vol. 174, No. 1-3, 2010, pp. 145-149. doi:10.1016/j.mseb.2010.03.006

[11] M. Caglar, S. Ilican and Y. Caglar, "Influence of Dopant Concentration on the Optical Properties of ZnO: In Films by Sol-Gel Method," Thin Solid Films, Vol. 517, No. 17, 2009, pp. 5023-5028. doi:10.1016/j.tsf.2009.03.037 